\title{
Photoelectrocatalytic Cross-Dehydrogenative Coupling of Unactivated Aliphatic Hydrogen Donors with Benzothiazoles: Synthetic Applications and Mechanistic Insights
}

\author{
Luca Capaldo,‡ Lorenzo L. Quadri,‡ Daniele Merli, Davide Ravelli* \\ PhotoGreen Lab, Department of Chemistry, University of Pavia, Viale Taramelli 12, 27100 Pavia, Italy \\ Benzothiazoles, Cross-Dehydrogenative Coupling, Hydrogen Atom Transfer, Photoelectrocatalysis, Radical Chemistry
}

\begin{abstract}
We report herein a photoelectrocatalytic strategy for the smooth preparation of 2-alkylbenzothiazoles via the cross-dehydrogenative coupling of unactivated aliphatic hydrogen donors (e.g. alkanes) with benzothiazoles. We used tetrabutylammonium decatungstate (TBADT) as the photocatalyst to cleave the strong $\mathrm{C}\left(\mathrm{sp}^{3}\right)-\mathrm{H}$ bonds embedded in the chosen substrates via Hydrogen Atom Transfer (HAT), while electrochemistry ensured the success of this net-oxidative transformation by scavenging the extra electrons. The reaction progress was monitored through kinetic analysis, highlighting the transient formation of the redox-neutral adduct 2-alkylbenzothiazoline. Further cyclic voltammetry and laser flash photolysis experiments unveiled the chameleonic behavior of TBADT that features a three-fold role: HAT photocatalyst to activate alkanes, photoredox catalyst to activate the 2-alkylbenzothiazoline and electrocatalyst to promote the oxidation of shortlived radical intermediates. The adopted potentiostatic mode allowed to tame the multi-faceted reactivity of TBADT and to ensure its recovery after each catalytic cycle with a very high faradaic efficiency. We proved the versatility of the proposed approach by replacing the potentiostat with a couple of cheap batteries in the preparation of the desired products.
\end{abstract}

\section{Introduction}

Recently, the successful combination of photocatalysis ${ }^{1}$ and electrochemistry ${ }^{2,3}$ has opened new avenues in synthesis, ${ }^{4-6}$ offering unparalleled mild operative conditions and contributing to address the urgent need of developing sustainable synthetic protocols. ${ }^{7}$ Contrary to the traditional "photoelectrochemical" approach based on an electrochemical cell equipped with a photoactive electrode, $, 5,8$ the newborn "photoelectrocatalysis" (PEC) features the productive interplay between a homogeneous photocatalytic system and the electrodes of a cell, exchanged electrons/holes being the only point of contact between them (Scheme 1a).4a Typically, the employed photocatalyst (PC) absorbs light and, once in the excited state ( $\mathrm{PC}^{*}$ ), smoothly activates the chosen substrate delivering a high-energy intermediate (an open-shell species) to be exploited for the desired chemistry. On the other hand, electrochemistry takes care of photocatalyst recovery ${ }^{9}$ and of adjusting the redox state of the involved intermediates, which enables non-redox neutral transformations in the absence of any chemical redox agent.

A seminal example of this chemistry was reported by the $\mathrm{Xu}$ group last year and dealt with the alkylation of (hetero)arenes by a variety of alkyltrifluoroborates (Scheme 1b). ${ }^{10}$ In the process, a C-centered radical ( $\mathrm{R}^{\cdot}$ ) was formed upon mono-electronic oxidation of the substates $\mathrm{R}_{-\mathrm{BF}_{3}}$ (potassium salts) by the excited mesitylacridinium (Mes$\mathrm{Acr}^{+}$) photocatalyst and ensuing loss of $\mathrm{BF}_{3}$. Then, $\mathrm{R} \cdot$ added onto the chosen aromatic nucleus $\mathrm{Ar}-\mathrm{H}$, ultimately leading to the formation of a new $\mathrm{C}\left(\mathrm{sp}^{3}\right)-\mathrm{Ar}$ bond via a further oxidation/deprotonation sequence.
Scheme 1. Photoelectrocatalysis Concept (a), Photoelectrocatalysis via Single-Electron Transfer (SET; b, Ref. 10) and via Hydrogen-Atom Transfer (HAT; c, this work).

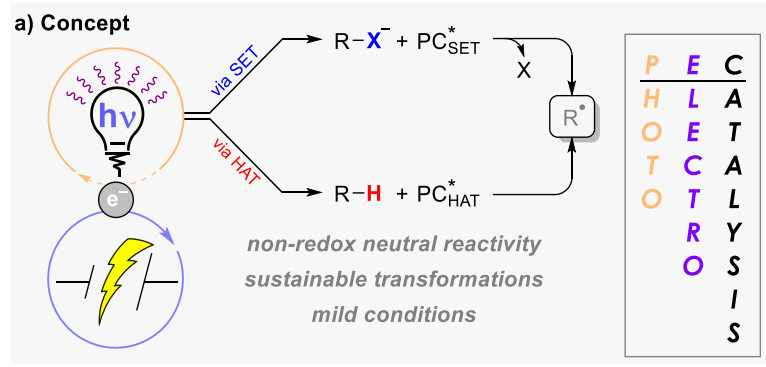

b) Photoelectrocatalysis via Single-Electron Transfer (SET)

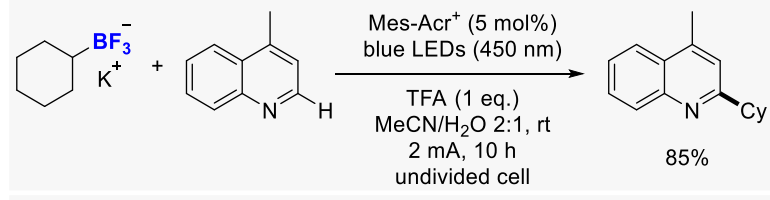

c) Photoelectrocatalysis via Hydrogen-Atom Transfer (HAT)

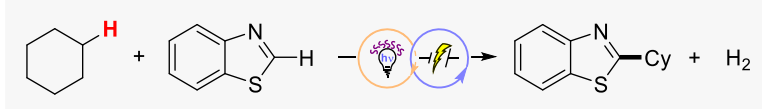

More recently, the carbamoylation (from oxamate salts) $^{11}$ and trifluoromethylation (from Langlois' reagent, $\left.\mathrm{CF}_{3} \mathrm{SO}_{2}-\mathrm{Na}^{+}\right)^{12}$ of (hetero)arenes by means of PEC have been likewise reported. Notably, all these strategies rely on the use of easily oxidizable anionic substrates ( $\mathrm{R}-\mathrm{X}^{-}$), prone to undergo a facile single-electron transfer (SET) 
with the excited photocatalyst (PC* ${ }^{*}$ ET). This is made possible by the presence of a suitable redox-auxiliary ${ }^{13}$ functional group $(\mathrm{X})$ embedded in the substrate that facilitates and drives the initial electron transfer step, ultimately being lost in the form of a stable molecule $\left(\mathrm{X}=\mathrm{BF}_{3}, \mathrm{CO}_{2}, \mathrm{SO}_{2}\right)$ during the process.

A much more convenient and straightforward strategy would require starting from substrates containing an unactivated $\mathrm{C}\left(\mathrm{sp}^{3}\right)-\mathrm{H}$ bond, in an overall crossdehydrogenative coupling (CDC) process. ${ }^{6 c, 14}$ In such case, the formation of the desired radical is entrusted to a photocatalyst ( $\mathrm{PC}_{\mathrm{HAT}}$ ) able, when in the excited state, to cleave homolytically the targeted $\mathrm{C}-\mathrm{H}$ bond via a direct hydrogenatom transfer (d-HAT) step. ${ }^{15}$ To the best of our knowledge, a photoelectrocatalytic strategy based on the merging between a $\mathrm{PC}_{\mathrm{HAT}}$ and electrochemistry has never been reported (Scheme 1c), even though a HAT step has been invoked in a few instances within synthetic strategies encompassing the combination of photochemistry and electrochemistry (see Scheme S1 in the Supporting Information). These include: i) the dual-catalytic oxidation of alcohols promoted by a flavin photocatalyst combined with a thiourea co-catalyst ${ }^{16}$ and ii) the electrophotocatalytic arylation of ethers catalyzed by a trisaminocyclopropenium $\left(\mathrm{TAC}^{+}\right)$derivative. ${ }^{17}$ Thus, these strategies can be applied only to compounds featuring rather labile $\alpha$-to- $\mathrm{O}-\mathrm{H}$ bonds. A HAT step has been likewise described in a couple of reports wherein photochemistry and electrochemistry share distinct and independent roles in the overall synthetic sequence. A recent example involves the CDC between aliphatic $\mathrm{C}-\mathrm{H}$ bonds and heteroarenes by in-situ electrogenerated $\mathrm{Cl}_{2},{ }^{18}$ while another instance is related to the dehydrogenative coupling between $\mathrm{C}\left(\mathrm{sp}^{3}\right)-\mathrm{H}$ and $\mathrm{N}-\mathrm{H}$ bonds in the presence of iodide, which functioned as electrochemical mediator. ${ }^{19}$

Following our interest in the discovery of synthetic strategies and relying on our expertise in the development of photocatalytic methodologies based on d-HAT, we hereby report our results on the development of a PEC strategy enabling the CDC of benzothiazoles and strong (unactivated) aliphatic $\mathrm{C}-\mathrm{H}$ bonds. Beside the preparative aspect, particular attention has been devoted to mechanistic studies, intended to unveil the exact role of each component of the reaction and to maximize the efficiency of the proposed steps.

\section{Results and Discussion}

We chose to adopt tetrabutylammonium decatungstate (TBADT, $\left.\left(n \mathrm{Bu}_{4} \mathrm{~N}\right)_{4}\left[\mathrm{~W}_{10} \mathrm{O}_{32}\right]\right)$ as $\mathrm{PC}_{\mathrm{HAT}}$, due to its robustness and the noteworthy properties in catalyzing the $\mathrm{C}-\mathrm{H}$ functionalization of a variety of aliphatic derivatives under irradiation. ${ }^{20,21}$ We built upon our previous work on the TBADT-photocatalyzed Minisci-type CDC of H-donors with heteroarenes, which took place in the presence of potassium persulfate $\left(\mathrm{K}_{2} \mathrm{~S}_{2} \mathrm{O}_{8}, 2\right.$ equiv.) as the terminal oxidant. ${ }^{22}$ We started off by investigating the oxidative coupling of cyclohexane (1a) and benzothiazole (2a) to give 2cyclohexylbenzothiazole (3) to test the behavior of TBADT under PEC, chemical oxidant-free, conditions.

We adopted a conventional H-type electrochemical cell as the reaction vessel, with the two compartments sepa- rated by a polymeric membrane (Nafion $\left.{ }^{\circledR} \mathrm{N}-117\right)$. A threeelectrodes system was implemented, where the working electrode (WE, anode) and the reference electrode (RE, $\mathrm{Ag} / \mathrm{AgCl}$, sat.d $\mathrm{NaCl}$ ) were placed in the anodic compartment, while the counter electrode (CE, cathode) was placed in the cathodic one. An LED lamp ( $\lambda_{\mathrm{em}}=390 \mathrm{~nm} ; 40$ $W)$ was used to irradiate the anodic compartment containing the reaction mixture, while temperature was kept below $30{ }^{\circ} \mathrm{C}$ by fan cooling. All reactions were conducted under rigorous oxygen-free conditions, by using freezepump-thawed solutions and operating under a positive pressure of Argon.

Thus, a solution of cyclohexane (1a, $0.25 \mathrm{M} ; 5$ equiv), benzothiazole (2a, $0.05 \mathrm{M}$ ), TBADT ( $4 \mathrm{~mol} \%$ ) and lithium bis(trifluoromethanesulfonyl)imide (LiNTf $; 0.05 \mathrm{M}$ ) as the electrolyte in $\mathrm{MeCN} / \mathrm{H}_{2} \mathrm{O} 10: 1$ was placed in the anodic compartment and irradiated for 20 hours in the presence of a glassy carbon electrode (GC, 3 rods, ø: $3 \mathrm{~mm}$; total exposed surface: $c a .20 \mathrm{~cm}^{2}$ ). As for the cathodic compartment, a $0.05 \mathrm{M} \mathrm{LiNTf}_{2}$ solution in water was used in the presence of a Pt-gauze electrode (dimensions: $4 \times 4 \mathrm{~cm}$; wire: $0.25 \mathrm{~mm}$; 25 mesh). Gratifyingly, when the cell was operated in a potentiostatic mode $\left(\Delta E_{\mathrm{WE}-\mathrm{RE}}=+150 \mathrm{mV}\right)$, we found that product 3 was formed in $80 \%$ NMR yield (at $>90 \%$ starting materials conversion; total charge: 1.9 F.mol-1; see Table 1, entry 1).

Table 1 . Survey of reaction conditions. ${ }^{a}$

\begin{tabular}{|c|c|c|c|c|}
\hline 1a, 5 & $\begin{array}{c}\text { TBADT }(4 \mathrm{~mol} \%) \\
40 \mathrm{~W} \text { LED Lamp }\left(\lambda_{\text {em }}=390 \mathrm{n}\right. \\
\Delta E_{\text {WE-RE }}=+150 \mathrm{mV} \\
\text { N117, Ar, } 20 \mathrm{~h} \\
\text { LiNTf }_{2}(0.05 \mathrm{M}) \\
\text { Pt }= \pm \text { C }\end{array}$ & $\pi^{c_{6} r}$ & $\theta$ & \\
\hline Entry & Variation from optimized conditions & 2a, Consumption & 3, Yield ${ }^{b}$ & $\mathrm{~F} \mathrm{~mol}^{-1}$ \\
\hline 1 & none & $>90 \%$ & $80 \%$ & 1.9 \\
\hline $2^{c}$ & $\mathrm{TBAClO}_{4}$ as the electrolyte & $83 \%$ & $43 \%$ & 0.8 \\
\hline 3 & LiOTf as the electrolyte & $73 \%$ & $42 \%$ & 0.9 \\
\hline 4 & $\mathrm{LiClO}_{4}$ as the electrolyte & $66 \%$ & $53 \%$ & 1.2 \\
\hline 5 & TBADT (1 mol\%) & $44 \%$ & $35 \%$ & 0.6 \\
\hline $6^{\mathrm{d}}$ & TBADT (8 mol\%) & $81 \%$ & $46 \%$ & 1.1 \\
\hline 7 & $\Delta E_{\mathrm{WE}-\mathrm{RE}}=0 \mathrm{mV}$ & $85 \%$ & $62 \%$ & 1.9 \\
\hline 8 & $\Delta E_{\mathrm{WE}-\mathrm{RE}}=+300 \mathrm{mV}$ & $75 \%$ & $55 \%$ & 1.5 \\
\hline $9^{\mathrm{e}}$ & amperostatic mode $(2 \mathrm{~mA})$ & $80 \%$ & $66 \%$ & 2 \\
\hline 10 & Carbon cloth as the anode & $83 \%$ & $64 \%$ & 2 \\
\hline 11 & $\mathrm{BDD}$ as the anode & $55 \%$ & $43 \%$ & 0.9 \\
\hline 12 & Pt gauze as the anode & $>90 \%$ & $80 \%$ & 2 \\
\hline 13 & undivided cell, Pt gauze as the anode & $23 \%$ & $16 \%$ & 1.6 \\
\hline 14 & no light, Pt gauze as the anode & $0 \%$ & n.d. & 0 \\
\hline $15^{f}$ & no TBADT, Pt gauze as the anode & $0 \%$ & n.d. & 0 \\
\hline 16 & no electrodes & $21 \%$ & traces $^{g}$ & - \\
\hline
\end{tabular}

a Reactions performed on a $0.75 \mathrm{mmol}$ scale in a standard H-type electrochemical cell, Nafion ${ }^{\circledR} \mathrm{N}-117$ membrane as the separator. Anolyte: 1a (0.25 M, 5 equiv), 2a (0.05 M), TBADT (4 mol\%), LiNTf 2 (0.05 M) in $\mathrm{MeCN} / \mathrm{H}_{2} \mathrm{O}$ 10:1 (15 mL). Catholyte: $\operatorname{LiNTf}_{2}(0.05 \mathrm{M})$ in $\mathrm{H}_{2} \mathrm{O}(15 \mathrm{~mL})$. b $\mathrm{NMR}$ yield, $\mathrm{CH}_{2} \mathrm{Br}_{2}$ as external standard. c $\mathrm{TBAClO}_{4}$ was poorly soluble. d Dirty reaction. e $2 \mathrm{~mA}$ was adopted to transfer $2 \mathrm{~F} \cdot \mathrm{mol}^{-1}$ within $20 \mathrm{~h}$. The formation of a thick deposit on the electrode surface was observed. f The experiment was stopped after 30 min since a very low current was observed ( $<1 \mathrm{~mA})$. GC: glassy carbon; Pt: Pt gauze electrode, BDD: boron-doped diamond (see SI for further information). g The redox-neutral adduct 2cyclohexylbenzothiazoline (3') was also formed in $9 \%$ yield. 
The reaction was rather sensitive to the nature of electrolyte used, with yields failing to reach 55\% when using tetrabutylammonium perchlorate or different Li-based salts (entries 2-4). Similarly, we found that $4 \mathrm{~mol} \%$ was the optimal catalyst loading. Only a limited conversion of $\mathbf{2 a}$ (44\%) was achieved in the presence of $1 \mathrm{~mol} \%$ TBADT (entry 5), while a poor mass balance associated with the formation of unidentified byproducts was observed when using 8 mol\% TBADT (entry 6).

Next, we considered the influence of the electrochemical parameters on the reaction outcome and modified the applied potential between WE and RE ( $\left.\Delta E_{\mathrm{WE}-\mathrm{RE}}\right)$, accordingly. However, albeit good conversion degrees were consistently obtained, the yield of 3 did not exceed $62 \%$ (entries 7, 8). Similarly, switching from a potentiostatic (constant potential applied) to an amperostatic (constant electric current applied, $2 \mathrm{~mA}$ for $20 \mathrm{~h}$ ) operation mode did not lead to any improvement, with formation of 3 in $66 \%$ yield and conversion of 2 a stopping at $80 \%$. Notably, the formation of a thick deposit on the surface of the anode was observed in the latter case, which caused the deterioration of electrode surface in the long term (entry 9). Hence, we screened alternative materials for the WE, including carbon cloth, boron-doped diamond (BDD) and Pt-gauze electrodes (entries 10-12). While carbon cloth and BDD allowed to obtain the expected product in modest to decent yields, product 3 was formed in $80 \%$ yield when using the noble metal electrode, indicating that Pt can be conveniently used as anodic material (entry 12). We also attempted to run the model reaction in a round bottom flask (undivided cell conditions), however a very poor performance was obtained (entry 13). Finally, control experiments indicated the essential role of light, photocatalyst and electricity (entries 14-16). Notably, under purely photocatalytic conditions, a small amount ( $9 \%$ yield) of the redox-neutral adduct 2-cyclohexylbenzothiazoline (3') was observed besides traces of product 3 (entry 16).
With the optimized conditions in hand (Table 1, entries 1 and 12), we next evaluated the scope of the reaction by investigating the reactivity of different $\mathrm{H}$-donors with parent benzothiazole $\mathbf{2 a}$, as shown in Table 2 . In doing so, we consistently adopted Pt gauze as the anode for its robustness and ease of cleaning, while selected entries were performed also with a GC electrode (see Table S1 in the SI). The model reaction allowed to isolate product 3 in $78 \%$ yield when 2a was reacted with 5 equiv of cyclohexane (1a); no improvement was observed if the excess of $\mathbf{1 a}$ was increased to 10 equiv (75\% isolated yield). On the other hand, in the case of cyclopentane (1b) a higher excess of H-donor was required to push the reaction to full conversion. Thus, the adoption of 20 equiv of $\mathbf{1 b}$ led to the isolation of adduct 4 in $73 \%$ yield, albeit the process maintained a very good mass balance in the presence of a lower 1b excess, as testified by the yields based on recovered starting material (brsm values). Norbornane (1c; 5 equiv. used) was smoothly functionalized to give the expected product 5 in $61 \%$ isolated yield $(77 \%$ brsm) as an exo/endo 8:1 mixture, along with a minor amount of 2(cyclopentylmethyl)benzothiazole $\left(\mathbf{5 A} ;<10 \%\right.$ yield). ${ }^{23}$ Due to solubility issues, we were not able to use higher concentrations of 1c to improve the yield. Similarly, cycloheptane (1d; 5 equiv. used) was scarcely soluble under our conditions, however the expected arylated adduct $\mathbf{6}$ and the dimerization product $\mathbf{6 A}$ were formed in 42 and $21 \%$ isolated yield, respectively. Finally, the selective functionalization $^{20 a}$ of isocapronitrile (1e; at the methine position) and cyclopentanone (1f; at the $\beta$-position with respect to the carbonyl) occurred in high isolated yields $(>80 \%)$ to give products 7 and 8 when using 10 equiv of the $\mathrm{H}$ donors. Consistently to what observed in the case of $\mathbf{1 b}, \mathbf{a}$ lower concentration of the H-donor led to a partial conversion of starting materials, while maintaining an excellent mass balance.

\section{Table 2. Scope of the reaction.}

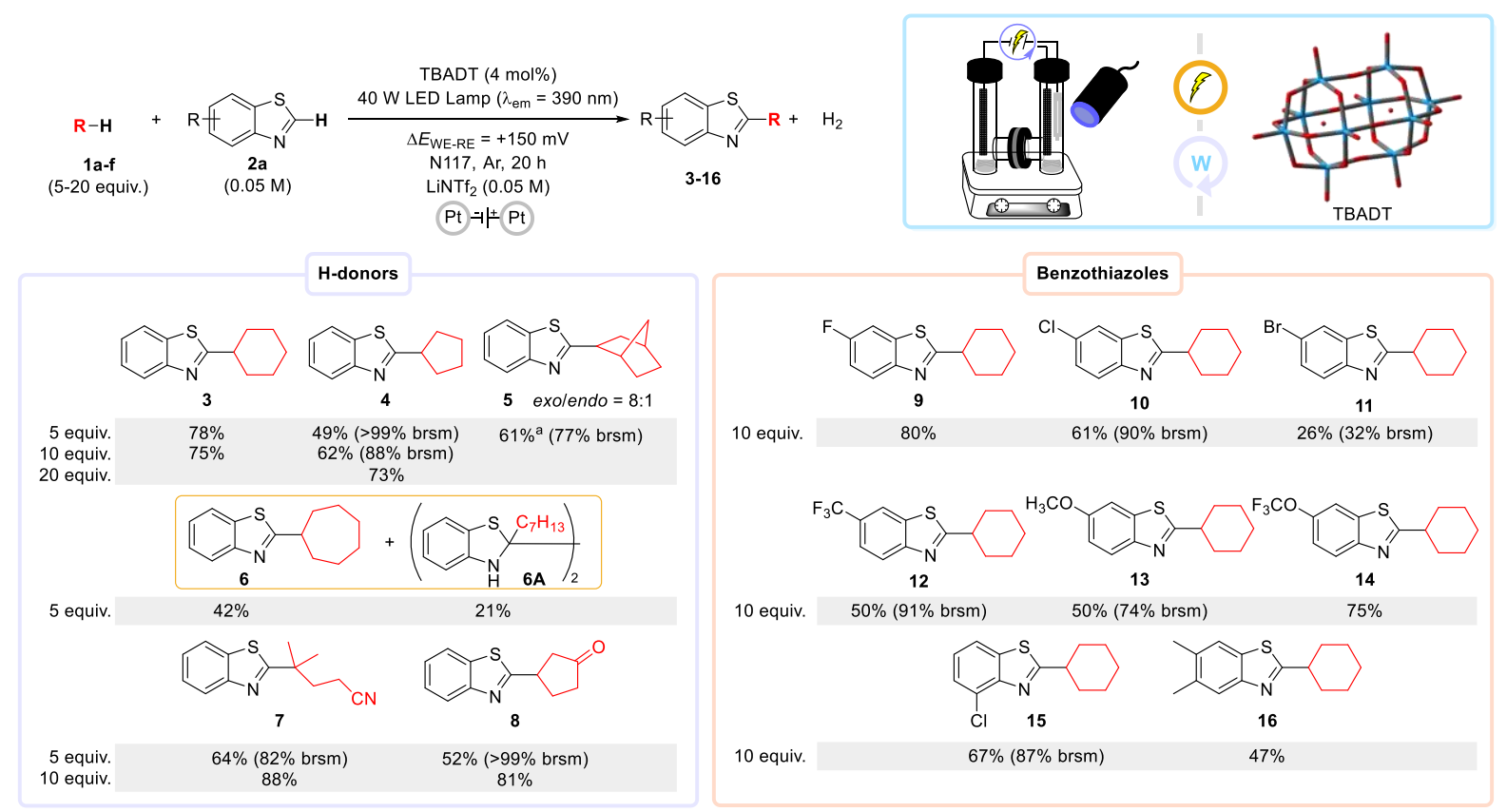

a A minor amount (ca. 8\% yield) of 2-(cyclopentylmethyl)benzothiazole (5A) was formed as well. 
Next, we turned our attention to the scope of the process in terms of benzothiazoles and selected $\mathbf{1 a}$ as the model Hdonor (10 equiv). Halogenated derivatives in the 6position were first tested and offered different reactivity profiles depending on the halogen nature. Indeed, fluorinated product 9 was isolated in an excellent $80 \%$ yield, while chlorinated product 10 was obtained in $61 \%$ isolated yield, albeit with a very good mass balance (90\% brsm). On the other hand, brominated product $\mathbf{1 1}$ was formed in a low yield (26\%). Strong electron-withdrawing or electrondonating substituents offered similar results, as testified by the cases of $6-\mathrm{CF}_{3}$ and 6-OMe adducts 12 and 13, that were both isolated in $50 \%$ yield (the former with a better mass balance). The biologically-relevant trifluoromethoxy group ${ }^{24}$ was tolerated as well, product 14 being obtained in $75 \%$ yield. Finally, we varied the number and position of the substituents on the starting benzothiazole. 4Chlorobenzothiazole afforded 15 in $67 \%$ yield $(87 \%$ brsm), while 5,6-dimethylbenzothiazole led to the formation of 16 in a modest yield (47\%).

At this stage, we turned to the study of the reaction mechanism and started off by monitoring the progress of the reaction between $\mathbf{1 a}$ and $\mathbf{2 a}$ over time (Figure 1a). In particular, we subjected aliquots of the reaction mixture to ${ }^{1} \mathrm{H}-\mathrm{NMR}$ analysis at regular time intervals and found that the redox-neutral adduct 2-cyclohexylbenzothiazoline ( 3 ') was formed at short reaction times, along with the desired product 3. However, while the latter kept accumulating in solution, the concentration of $\mathbf{3}$ ' reached a maximum (at $c a .1 \mathrm{~h}$ ) and then started to decrease, being completely consumed at the end of the reaction $(20 \mathrm{~h})$. By contrast, the current flowing through the cell peaked at $c a .5 .5 \mathrm{~mA}$ within the first ten minutes from the beginning of the reaction, then settled to a $3 \mathrm{~mA}$ plateau from 1 to $7 \mathrm{~h}$ (see gray line shown in the background).

We also assessed the faradaic efficiency (FE) throughout the reaction course (see Figure $1 \mathrm{~b}$ ) by comparing the chemical yield of $\mathbf{3}$ (the only net-oxidation product formed, blue line referred to left axis) with the amount of charge flowing through the cell (red line referred to right axis). Upon adjusting the scale of the two axes by considering that two moles of electrons are required in an ideal scenario per mole of $\mathbf{3}$ formed, it is noteworthy that the two traces are almost superimposable (FE $\approx 100 \%$ ) until $c a .10 \mathrm{~h}$. After this time, the blue line flattens out while the red one keeps increasing, with FE decreasing to a $c a$. $80 \%$ final value. Furthermore, we demonstrated the direct connection between the photocatalytic system and the current flowing through the cell by switching the light on and off at regular time intervals ( 5 min., Figure $1 \mathrm{c}$ ). We found that the current intensity increases steadily during the irradiation periods, while starts decreasing immediately after turning the light off. Notably, this behavior is replicable for multiple cycles with minimal changes.

In the second part of our mechanistic investigation, we addressed in more detail the reactivity of the redoxneutral adduct 3' (Scheme 2). Thus, when subjected to optimized PEC conditions, $\mathbf{3}$ ' was readily converted to the final product 3 in $60 \%$ NMR yield (Scheme $2 \mathrm{a}$ ). On the contrary, when the process was performed in the dark, no traces of $\mathbf{3}$ were observed, with $\mathbf{3}$ ' being recovered unreacted (Scheme 2b, see SI for further information).
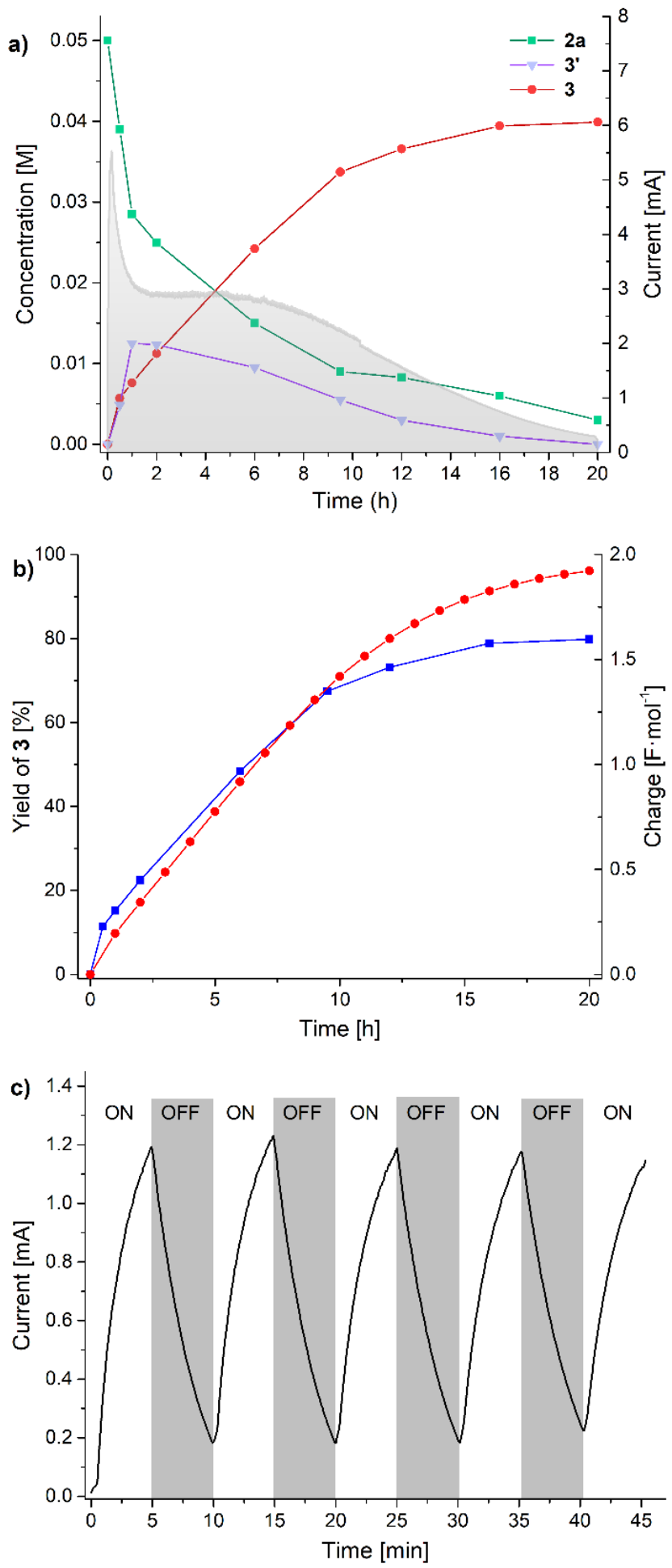

Figure 1. a) Kinetic study of the model reaction between cyclohexane 1a and benzothiazole 2a. b) Comparison of the chemical yield of $\mathbf{3}$ and the amount of charge passed through the cell. c) Light ON-OFF experiment. 
Scheme 2. Control Experiments.
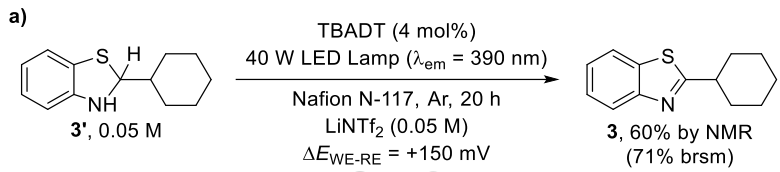

b) $\mathrm{Pt}=1+\mathrm{Pt}$
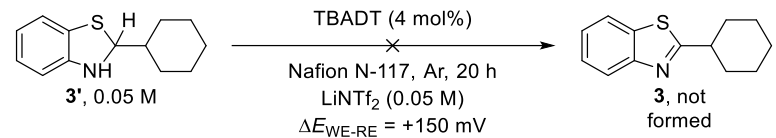

Pt $=1 \mid+\mathrm{Pt}$

Reactivity studies on adduct 2-cyclohexylbenzothiazoline (3') under optimized photoelectrocatalytic (a) and purely electrochemical (b) conditions.

We also performed laser flash photolysis (LFP) experiments to study the decay of the reactive excited state of decatungstate (tagged w0), which can be monitored at 780 $\mathrm{nm}$ (see SI for additional details). ${ }^{20 \mathrm{~d}, 25}$ Thus, after verifying that LiNTf $_{2}$ does not act as a quencher of w0, we measured the quenching constants for $\mathbf{1 a}$ and $\mathbf{3}$ ' under the present reaction conditions. As for the former, a bimolecular rate constant $k_{Q}(\mathbf{1 a})=3.3 \times 10^{8} \mathrm{M}^{-1} \cdot \mathrm{s}^{-1}$ was determined, ${ }^{26}$ while 3' quenched w0 with a nearly diffusion-controlled bimolecular rate constant, $k_{\mathrm{Q}}\left(3^{\prime}\right)>10^{9} \mathrm{M}^{-1} \cdot \mathrm{s}^{-1}$. Furthermore, upon careful inspection of the shape of the recorded spectral traces, we ascertained that the activation of $\mathbf{1 a}$ and $\mathbf{3}$ occurs via HAT and SET, respectively (for additional details, see SI). ${ }^{25}$

Taken together, the data report above depict the mechanistic scenario proposed in Scheme 3a. Thus, light excitation of the dectungstate anion triggers the typical HAT reactivity of w0 towards unactivated aliphatic substrates (e.g. 1a). This step delivers a nucleophilic C-centered radi- cal $\left(\mathbf{I}^{\bullet}\right)$, which adds onto the 2-position of benzothiazole (e.g. 2a) to afford radical adduct II $^{\bullet}$. At this stage, $\mathbf{I I}^{\bullet}$ may follow two different pathways to be ultimately converted to product 3.

One possibility is that II' undergoes a back-HAT (b-HAT) from the reduced form of decatungstate $\mathrm{H}^{+}\left[\mathrm{W}_{10} \mathrm{O}_{32}\right]^{5-}\left(\mathrm{W}_{\text {red }}\right.$ $\left(\mathrm{H}^{+}\right)$to give the redox-neutral benzothiazoline derivative 3', also restoring the original form of the photocatalyst (path $a$ ). At this stage, $\mathbf{3}$ ' is oxidized to $\mathbf{3}$ via a photoelectrocatalytic sequence, wherein w0 triggers an oxidative SET event to deliver intermediate III• upon deprotonation.

Alternatively, the formation of the final product $\mathbf{3}$ from II can occur via path $b$ : we suggest that II- undergoes a spin-center shift (SCS), ${ }^{27,28}$ possibly mediated by the protic medium, ${ }^{29}$ to give III: Notably, the intermediacy of this species is corroborated by the outcome of the reaction between cycloheptane $\mathbf{1 d}$ and benzothiazole $\mathbf{2 a}$, wherein the formation of $\mathbf{6 A}$ can be explained via the dimerization of the corresponding III• species, accumulating in solution due to an inefficient conversion to 6.

As for the fate of III* following a previously reported approach, ${ }^{10}$ we estimated its oxidation potential by measuring the reduction potential of the protonated product $3-\mathbf{H}^{+}$

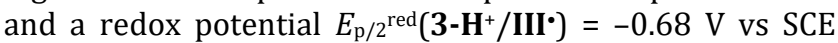
has been found (see Scheme $3 \mathrm{~b}$ and SI for additional details). However, due to the transient nature of III', we consider its direct oxidation by the anode unlikely and postulate that the decatungstate anion might serve as an electrocatalyst to promote this step. The analysis of the redox behavior of TBADT through cyclic voltammetry has been previously reported, indicating a reduction event at -0.97 $\mathrm{V}$ vs SCE in MeCN. ${ }^{30}$ However, in our conditions the abovementioned reduction event shifts to a less negative potential, viz. $E_{\mathrm{p} / 2^{\text {red }}}\left(\mathrm{W} / \mathrm{W}_{\text {red }}\right)=-0.52 \mathrm{~V}$ vs SCE (Scheme $3 \mathrm{c}$ and SI), fully supporting the proposed role of decatungstate as electrocatalyst.

\section{Scheme 3. Mechanistic Proposal.}
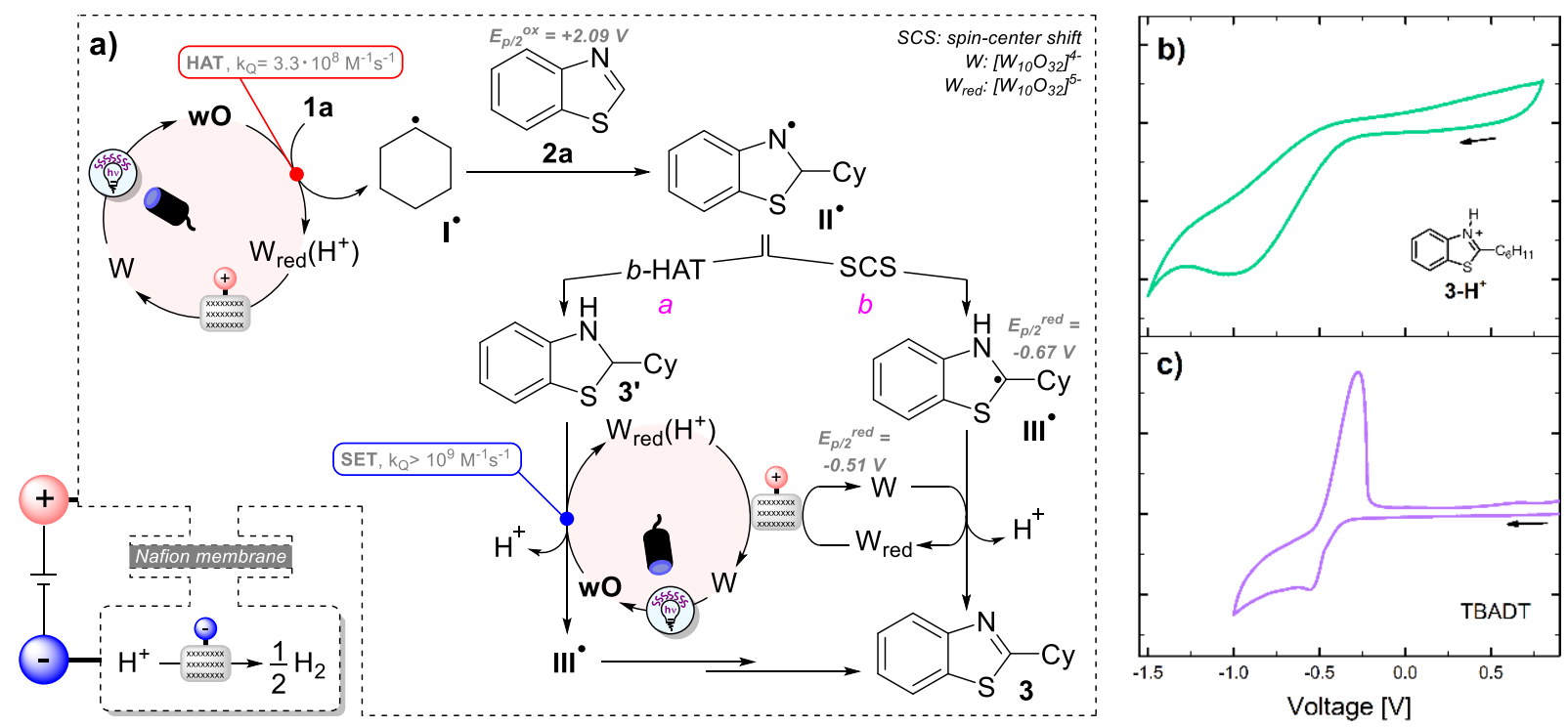

Proposed reaction mechanism (a) and cyclic voltammetry analysis of relevant species (b and c). 
Turning to the cathodic events, the reaction of $1 \mathbf{a}$ and $2 \mathbf{a}$ to give 3 leads to the overall generation of 2 electrons and 2 protons, which are then recombined to produce hydrogen gas.

It is worth noting that different mechanistic interpretations can be discarded based on the results obtained from control experiments. First of all, the very low applied potential $\left(\Delta E_{\mathrm{WE}-\mathrm{RE}}=+150 \mathrm{mV}\right)$ is not sufficient to oxidize any of the employed aromatic substrates (see Electrochemical study in the SI). Likewise, we can exclude that the formation of $\mathbf{3}$ occurs through a distinct sequence involving the initial photocatalytic formation of 3' (see Table 1, entry 16) and the ensuing electrochemical oxidation of 3 ' to 3 (see Scheme $2 \mathrm{~b}$ and cyclic voltammetry analysis in the SI). On the other hand, we may speculate about the relative importance of paths $a$ vs $b$ (Scheme 3a), in other words: is the formation of $\mathbf{3}$ ' a prerequisite on the route to $\mathbf{3}$ ? To this end, we compared the data gathered in Figure 1a with an ideal kinetic model for two consecutive reactions (Figure S8). While an overall good agreement among experimental and simulated data was found, the consecutive reactions model implies a certain induction period for the formation of product 3, which is not observed in the experiment. Accordingly, we can confirm that the direct formation of $\mathbf{3}$ from $1 \mathbf{a}+\mathbf{2 a}$ occurs, especially in the initial period of the process, when most of the employed catalyst is present in solution in its oxidized form (W), thus behaving as electrocatalyst and favoring path $b$ over path $a$.

Finally, to assess the robustness of the reaction and its operational simplicity, we replaced the expensive and cumbersome potentiostat with tiny, cheap batteries. To this end, we operated our PEC system in a 2-electrodes setup by using two $1.5 \mathrm{~V}$ batteries (AAA-type) connected in series to apply a $\sim 3 \mathrm{~V}$ voltage in place of the potentiostat. Gratifyingly, product 3 was formed in 65\% yield (by NMR; $73 \% \mathrm{brsm}$ ) upon irradiation for $20 \mathrm{~h}$. We also monitored (every hour) the current flow within the cell under these conditions, observing a constant $3 \mathrm{~mA}$ current for the first $5 \mathrm{~h}$ from the beginning of the reaction, while the value dropped to $c a .1 \mathrm{~mA}$ towards the end, reminiscent of the trend observed when using the potentiostat (see Figure 1a).

\section{Conclusions}

The obtained products contain the benzothiazole ring, an important structural motif in several bioactive compounds. ${ }^{31}$ In particular, 2-alkyl substituted benzothiazoles, among the other applications, have been adopted as anticancer, antimicrobial, antitubercular, antidiabetic and antidepressant agents. ${ }^{31 a}$ The hereby reported approach offers a complementary strategy to alternative radicalmediated Minisci-type protocols, which are often biased towards the functionalization of 6-membered heteroarenes. ${ }^{14,32}$ Furthermore, this PEC protocol, wherein electricity functions as the terminal oxidant, compares favorably with our previous work based on the use of a chemical oxidant (excess $\mathrm{K}_{2} \mathrm{~S}_{2} \mathrm{O}_{8}$ ). ${ }^{22}$ In particular, compound 3 was prepared in $60 \%$ isolated yield adopting the latter method, while photoelectrocatalysis allowed to improve this value (up to 78\%) with the adoption of a lower $\mathrm{H}$-donor excess (5 equiv vs 20 equiv).
Overall, the present work unlocks the use of aliphatic substrates featuring strong $\mathrm{C}\left(\mathrm{sp}^{3}\right)-\mathrm{H}$ bonds in photoelectrocatalytic manifolds and enables their arylation with benzothiazoles in a cross-dehydrogenative coupling protocol. The success of this protocol is based on the productive merger between decatungstate photocatalysis and the electrochemical cell, responsible for activating the involved organic derivatives upon irradiation and adjusting the redox balance of the formed intermediates, respectively. Mechanistic investigations allowed to ascertain the temporary formation of a 2-alkylbenzothiazoline adduct, which was then converted to the final product. Notably, the decatungstate anion shows a chameleonic attitude in enabling the reported transformation and plays a three-fold role, as HAT photocatalyst, photoredox catalyst and electrocatalyst. The process occurs under extremely mild conditions and with a very low applied potential, resulting in a perfect matching with the reactivity profile offered by TBADT, that is turned over after each catalytic cycle with an excellent faradaic efficiency. Further studies related to the use of the decatungstate anion in photoelectrocatalytic protocols are currently ongoing in our laboratory.

\section{ASSOCIATED CONTENT}

Supporting Information. Experimental details about the used materials, sample preparation, electrochemical measurements, laser flash photolysis, kinetic analysis and copy of NMR spectra. This material is available free of charge via the Internet at http://pubs.acs.org.

\section{AUTHOR INFORMATION}

\section{Corresponding Author}

* Davide Ravelli - PhotoGreen Lab, Department of Chemistry, University of Pavia, Viale Taramelli 12, 27100 Pavia, Italy. orcid.org/0000-0003-2201-4828

Email: davide.ravelli@unipv.it

\section{Authors}

Luca Capaldo - PhotoGreen Lab, Department of Chemistry, University of Pavia, 27100 Pavia, Italy.

orcid.org/0000-0001-7114-267X

Lorenzo L. Quadri - PhotoGreen Lab, Department of Chemistry, University of Pavia, 27100 Pavia, Italy.

orcid.org/0000-0002-1400-4753

Daniele Merli - Department of Chemistry, University of Pavia, 27100 Pavia, Italy. orcid.org/0000-0003-3975-0127

\section{Author Contributions}

L.C. and L.L.Q. performed the experiments. D.M. supervised the electrochemical part of the work. D.R. wrote the paper and supervised the work.

₹ L.C. and L.L.Q. contributed equally to this work.

\section{Funding Sources}

The authors acknowledge Fondazione CARIPLO (grant n. 2018-2627) and the University of Pavia (InROAd project "ElectroLight") for financial support. 
Notes

The authors declare no competing financial interest.

\section{ACKNOWLEDGMENT}

We gratefully thank Prof. Mariella Mella, Teresa Recca and Luca Ferrari (University of Pavia) for fruitful discussion.

\section{REFERENCES}

(1) a) Visible Light Photocatalysis in Organic Chemistry (Eds.: Stephenson, C. R. J; Yoon, T. P.; MacMillan, D. W. C.), Wiley, Hoboken, 2018; b) Chemical Photocatalysis (Ed.: König, B.), De Gruyter, Berlin, 2013; c) Ravelli, D.; Protti, S.; Fagnoni, M. Carbon-Carbon Bond Forming Reactions via Photogenerated Intermediates. Chem. Rev. 2016, 116 (17) 9850-9913. https://doi.org/10.1021/acs.chemrev.5b00662; d) Romero, N. A.; Nicewicz, D. A. Organic Photoredox Catalysis. Chem. Rev. 2016, 116 (17), 10075-10166. https://doi.org/10.1021/acs.chemrev.6b00057; e) Prier, C. K.; Rankic, D. A.; MacMillan, D. W. C. Visible Light Photoredox Catalysis with Transition Metal Complexes: Applications in Organic Synthesis. Chem. Rev. 2013, 113 (7), 5322-5363. https://doi.org/10.1021/cr300503r; f) Xuan, J.; Xiao, W.-J. Visible-Light Photoredox Catalysis. Angew. Chem. Int. Ed. 2012, 51 (28), 6828-6838. https://doi.org/10.1002/anie.201200223.

(2) a) Organic Electrochemistry: Revised and Expanded, 5th ed. (Eds.: Hammerich, O.; Speiser, B.), CRC, Boca Raton, 2015; b) Meyer, T. H.; Choi, I.; Tian, C.; Ackermann, L. Powering the Future: How Can Electrochemistry Make a Difference in Organic Synthesis? Chem 2020, 6 (10), 2484-2496.

https://doi.org/10.1016/j.chempr.2020.08.025; c) Little, R. D. A Perspective on Organic Electrochemistry. J. Org. Chem. 2020, 85 (21), 13375-13390. https://doi.org/10.1021/acs.joc.0c01408; d) Kawamata, Y.; Baran, P. S. Electrosynthesis: Sustainability Is Not Enough. Joule 2020, 4 (4), 701-704. https://doi.org/10.1016/j.joule.2020.02.002; e) Yan, M.; Kawamata, Y.; Baran, P. S. Synthetic Organic Electrochemical Methods Since 2000: On the Verge of a Renaissance. Chem. Rev. 2017, 117 (21), 13230-13319. https://doi.org/10.1021/acs.chemrev.7b00397; f) Wiebe, A.; Gieshoff, T.; Möhle, S.; Rodrigo, E.; Zirbes, M.; Waldvogel, S. R. Electrifying Organic Synthesis. Angew. Chem. Int. Ed. 2018, 57 (20), 5594-5619. https://doi.org/10.1002/anie.201711060.

(3) For electrocatalytic strategies applied to organic synthesis, see: a) Francke, R.; Little, R. D. Redox Catalysis in Organic Electrosynthesis: Basic Principles and Recent Developments. Chem. Soc. Rev. 2014, 43 (8), 2492. https://doi.org/10.1039/c3cs60464k; b) Nutting, J. E.; Rafiee, M.; Stahl, S. S. Tetramethylpiperidine N -Oxyl (TEMPO), Phthalimide N -Oxyl (PINO), and Related N Oxyl Species: Electrochemical Properties and Their Use in Electrocatalytic Reactions. Chem. Rev. 2018, 118 (9), 4834-4885.

https://doi.org/10.1021/acs.chemrev.7b00763.

(4) For homogeneous photocatalytic systems, see: a) Capaldo, L.; Quadri, L. L.; Ravelli, D. Merging Photocatalysis with Electrochemistry: The Dawn of a New Alliance in Organic Synthesis. Angew. Chem. Int. Ed. 2019, 58 (49), 1750817510. https://doi.org/10.1002/anie.201910348; b) Yu, Y.; Guo, P.; Zhong, J.-S.; Yuan, Y.; Ye, K.-Y. Merging Photochemistry with Electrochemistry in Organic Synthesis. Org. Chem. Front. 2020, 7 (1), 131-135. https://doi.org/10.1039/C9Q001193E; c) Barham, J. P.; König, B. Synthetic Photoelectrochemistry. Angew. Chem.

Int. $\quad E d . \quad \mathbf{2 0 2 0}, \quad 59 \quad$ (29), 11732-11747. https://doi.org/10.1002/anie.201913767.

(5)

For heterogeneous photocatalytic systems, see: a) Hardwick, T.; Qurashi, A.; Shirinfar, B.; Ahmed, N. Interfacial Photoelectrochemical Catalysis: Solar-Induced Green Synthesis of Organic Molecules. ChemSusChem 2020, 13 (8), 1967-1973 https://doi.org/10.1002/cssc.202000032; b) Wu, Y.-C.; Song, R.-J.; Li, J.-H. Recent Advances in Photoelectrochemical Cells (PECs) for Organic Synthesis. Org. Chem. Front. 2020, 7 (14), 1895-1902. https://doi.org/10.1039/D0Q000486C.

(6) For a comparison of photochemical vs electrochemical strategies, see: a) Liu, J.; Lu, L.; Wood, D.; Lin, S. New Redox Strategies in Organic Synthesis by Means of Electrochemistry and Photochemistry. ACS Cent. Sci. 2020, 6 (8), $1317-1340$ https://doi.org/10.1021/acscentsci.0c00549; b) Verschueren, R. H.; De Borggraeve, W. M. Electrochemistry and Photoredox Catalysis: A Comparative Evaluation in Organic Synthesis. Molecules 2019, $24 \quad$ (11), 2122 https://doi.org/10.3390/molecules24112122; c) Wang, H.; Gao, X.; Lv, Z.; Abdelilah, T.; Lei, A. Recent Advances in Oxidative R1-H/R2-H Cross-Coupling with Hydrogen Evolution via Photo-/Electrochemistry. Chem. Rev. 2019, $119 \quad$ (12), 6769-6787. https://doi.org/10.1021/acs.chemrev.9b00045.

(7) Horn, E. J.; Rosen, B. R.; Baran, P. S. Synthetic Organic Electrochemistry: An Enabling and Innately Sustainable Method. ACS Cent. Sci. 2016, 2 (5), 302-308. https://doi.org/10.1021/acscentsci.6b00091.

(8) For a seminal example, see: Fujishima, A.; Honda, K. Electrochemical Photolysis of Water at a Semiconductor Electrode. Nature 1972, 238 (5358), 37-38. https://doi.org/10.1038/238037a0.

(9) Capaldo, L.; Ravelli, D. The Dark Side of Photocatalysis: One Thousand Ways to Close the Cycle. Eur. J. Org. Chem. 2020, 2020 2783-2806. https://doi.org/10.1002/ejoc.202000144.

(10) Yan, H.; Hou, Z.; Xu, H. Photoelectrochemical C-H Alkylation of Heteroarenes with Organotrifluoroborates. Angew. Chem. Int. $\quad E d . \quad 2019, \quad 58 \quad$ (14), 4592-4595. https://doi.org/10.1002/anie.201814488.

(11) Lai, X.; Shu, X.; Song, J.; Xu, H. Electrophotocatalytic Decarboxylative $\mathrm{C}-\mathrm{H}$ Functionalization of Heteroarenes. Angew. Chem. Int. Ed. 2020, 59 (26), 10626-10632. https://doi.org/10.1002/anie.202002900.

(12) Qiu, Y.; Scheremetjew, A.; Finger, L. H.; Ackermann, L. Electrophotocatalytic Undirected $\mathrm{C}-\mathrm{H}$ Trifluoromethylations of (Het)Arenes. Chem. Eur. J. 2020, 26 (15), 3241-3246. https://doi.org/10.1002/chem.201905774.

(13) Tyson, E. L.; Farney, E. P.; Yoon, T. P. Photocatalytic [2+2] Cycloadditions of Enones with Cleavable Redox Auxiliaries. Org. Lett. 2012, 14 (4), 1110-1113. https://doi.org/10.1021/ol3000298.

(14) a) Bagdi, A. K.; Rahman, M.; Bhattacherjee, D.; Zyryanov, G. V.; Ghosh, S.; Chupakhin, O. N.; Hajra, A. Visible Light Promoted Cross-Dehydrogenative Coupling: A Decade Update. Green Chem. 2020, 22 (20), 6632-6681. https://doi.org/10.1039/D0GC02437F; b) Luo, W.; Yang, K.; Yin, B. Recent Progress in Radical Alkylation of Heteroarenes Based on $\mathrm{C}\left(\mathrm{sp}^{3}\right)-\mathrm{H}$ Bond Cleavage Strategy. Chinese J. Org. Chem. 2020, $40 \quad$ (8), 2290. https://doi.org/10.6023/cjoc202004024.; c) Varun, B. V.; Dhineshkumar, J.; Bettadapur, K. R.; Siddaraju, Y.; Alagiri, K.; Prabhu, K. R. Recent Advancements in Dehydrogenative Cross Coupling Reactions for C-C Bond Formation. Tetrahedron Lett. $\quad 2017, \quad 58 \quad$ (9), 803-824. https://doi.org/10.1016/j.tetlet.2017.01.035.

(15) a) Capaldo, L.; Quadri, L. L.; Ravelli, D. Photocatalytic Hydrogen Atom Transfer: The Philosopher's Stone for Late- 
Stage Functionalization? Green Chem. 2020, 22 (11), 33763396. https://doi.org/10.1039/D0GC01035A; b) Capaldo, L.; Ravelli, D. Hydrogen Atom Transfer (HAT): A Versatile Strategy for Substrate Activation in Photocatalyzed Organic Synthesis. Eur. J. Org. Chem. 2017, 2017 (15), 2056-2071. https://doi.org/10.1002/ejoc.201601485.

(16) Zhang, W.; Carpenter, K. L.; Lin, S. Electrochemistry Broadens the Scope of Flavin Photocatalysis: Photoelectrocatalytic Oxidation of Unactivated Alcohols. Angew. Chem. Int. Ed 2020, $59 \quad$ (1), 409-417. https://doi.org/10.1002/anie.201910300.

(17) Huang, H.; Strater, Z. M.; Lambert, T. H. Electrophotocatalytic C-H Functionalization of Ethers with High Regioselectivity. J. Am. Chem. Soc. 2020, 142 (4), 1698-1703 https://doi.org/10.1021/jacs.9b11472.

(18) Xu, P.; Chen, P.; Xu, H. Scalable Photoelectrochemical Dehydrogenative Cross-Coupling of Heteroarenes with Aliphatic C-H Bonds. Angew. Chem. Int. Ed. 2020, 59 (34) 14275-14280. https://doi.org/10.1002/anie.202005724.

(19) Wang, F.; Stahl, S. S. Merging Photochemistry with Electrochemistry: Functional-Group Tolerant Electrochemical Amination of $\mathrm{C}\left(\mathrm{sp}^{3}\right)-\mathrm{H}$ Bonds. Angew. Chem. Int. Ed. 2019, 58 (19), 6385-6390. https://doi.org/10.1002/anie.201813960.

(20) For reviews, see: a) Ravelli, D.; Fagnoni, M.; Fukuyama, T.; Nishikawa, T.; Ryu, I. Site-Selective C-H Functionalization by Decatungstate Anion Photocatalysis: Synergistic Control by Polar and Steric Effects Expands the Reaction Scope. ACS Catal. 2018, 8 (1), 701-713. https://doi.org/10.1021/acscatal.7b03354; b) Protti, S.; Ravelli, D.; Fagnoni, M.; Albini, A. Solar Light-Driven Photocatalyzed Alkylations. Chemistry on the Window Ledge. Chem. Commun. 2009, No. 47, 7351. https://doi.org/10.1039/b917732a; c) Tzirakis, M. D.; Lykakis, I. N.; Orfanopoulos, M. Decatungstate as an Efficient Photocatalyst in Organic Chemistry. Chem. Soc. Rev. 2009, 38 (9), 2609. https://doi.org/10.1039/b812100c; d) Tanielian, C. Decatungstate Photocatalysis. Coord. Chem. Rev. 1998, 178180, 1165-1181. https://doi.org/10.1016/S00108545(98)00160-X.

(21) For recent examples, see: a) Laudadio, G.; Deng, Y.; van der Wal, K.; Ravelli, D.; Nuño, M.; Fagnoni, M.; Guthrie, D.; Sun, Y. Noël, T. C $\left(\mathrm{sp}^{3}\right)-\mathrm{H}$ Functionalizations of Light Hydrocarbons Using Decatungstate Photocatalysis in Flow. Science 2020, 369 (6499), 92-96. https://doi.org/10.1126/science.abb4688; b) Cao, H.; Kuang, Y.; Shi, X.; Wong, K. L.; Tan, B. B.; Kwan, J. M. C.; Liu, X.; Wu, J Photoinduced Site-Selective Alkenylation of Alkanes and Aldehydes with Aryl Alkenes. Nat. Commun. 2020, 11 (1) 1956. https://doi.org/10.1038/s41467-020-15878-6; c) Kuang, Y.; Cao, H.; Tang, H.; Chew, J.; Chen, W.; Shi, X.; Wu, J. Visible Light Driven Deuteration of Formyl C-H and Hydridic $\mathrm{C}\left(\mathrm{sp}^{3}\right)-\mathrm{H}$ Bonds in Feedstock Chemicals and Pharmaceutical Molecules. Chem. Sci. 2020, 11 (33), 8912-8918. https://doi.org/10.1039/D0SC02661A; d) Wang, L.; Wang, T.; Cheng, G.-J.; Li, X.; Wei, J.-J.; Guo, B.; Zheng, C.; Chen, G.; Ran, C.; Zheng, C. Direct C-H Arylation of Aldehydes by Merging Photocatalyzed Hydrogen Atom Transfer with Palladium Catalysis. ACS Catal. 2020, 10 (14), 7543-7551. https://doi.org/10.1021/acscatal.0c02105; e) Dai, Z.-Y.; Nong, Z.-S.; Wang, P.-S. Light-Mediated Asymmetric Aliphatic C-H Alkylation with Hydrogen Atom Transfer Catalyst and Chiral Phosphoric Acid. ACS Catal. 2020, 10 (8), 4786-4790. https://doi.org/10.1021/acscatal.0c00610; f) Supranovich, V. I.; Levin, V. V.; Dilman, A. D. Radical Addition to $\mathrm{N}$ Tosylimines via $\mathrm{C}-\mathrm{H}$ Activation Induced by Decatungstate Photocatalyst. Org. Lett. 2019, 21 (11), 4271-4274 https://doi.org/10.1021/acs.orglett.9b01450; g) Perry, I. B.; Brewer, T. F.; Sarver, P. J.; Schultz, D. M.; DiRocco, D. A MacMillan, D. W. C. Direct Arylation of Strong Aliphatic C-H Bonds. Nature 2018, $560 \quad$ (7716), 70-75. https://doi.org/10.1038/s41586-018-0366-x.

(22) Quattrini, M. C.; Fujii, S.; Yamada, K.; Fukuyama, T.; Ravelli, D. Fagnoni, M.; Ryu, I. Versatile Cross-Dehydrogenative Coupling of Heteroaromatics and Hydrogen Donors via Decatungstate
Photocatalysis. Chem. Commun. 2017, 53 (15), 2335-2338. https://doi.org/10.1039/c6cc09725a

(23) We attribute the formation of $\mathbf{5 A}$ to an over-oxidation pathway. See: Sirtori, C.; Altvater, P. K.; deFreitas, A. M.; Peralta-Zamora, P. G. Degradation of aqueous solutions of camphor by heterogeneous photocatalysis. J. Hazard. Mater. 2006, $129 \quad$ (1-3), 110-115. https://doi.org/10.1016/j.jhazmat.2005.08.017.

(24) Leroux, F. R.; Manteau, B.; Vors, J.-P.; Pazenok, S Trifluoromethyl Ethers - Synthesis and Properties of an Unusual Substituent. Beilstein J. Org. Chem. 2008, 4. https://doi.org/10.3762/bjoc.4.13.

(25) Texier, I.; Delaire, J. A.; Giannotti, C. Reactivity of the Charge Transfer Excited State of Sodium Decatungstate at the Nanosecond Time Scale. Phys. Chem. Chem. Phys. 2000, 2 (6), 1205. https://doi.org/10.1039/a908588b.

(26) This value is significantly higher than that found in neat MeCN $\left(2.3 \times 10^{7} \mathrm{M}^{-1} \cdot \mathrm{s}^{-1}\right)$, in accordance with that previously reported in the literature, namely $k_{0}(1 \mathbf{a}$ in $\mathrm{MeCN})=4.0 \times 10^{7}$ $\mathrm{M}^{-1} \cdot \mathrm{s}^{-1}$. See: Dondi, D.; Fagnoni, M.; Albini, A. Chem. Eur. J. 2006, 12 (15), 4153-4163. DOI: 10.1002/chem.200501216.

(27) Wessig, P.; Muehling, 0. Spin-Center Shift (SCS) - A Versatile Concept in Biological and Synthetic Chemistry. Eur. J. Org. Chem. 2007, 2007 (14), 2219-2232. https://doi.org/10.1002/ejoc.200600915.

(28) For previous examples of photocatalytic processes involving a spin-center shift, see: a) Jin, J.; MacMillan, D. W. C. Alcohols as Alkylating Agents in Heteroarene C-H Functionalization. Nature $\quad 2015, \quad 525$ (7567), 87-90. https://doi.org/10.1038/nature14885; b) Nacsa, E. D.; MacMillan, D. W. C. Spin-Center Shift-Enabled Direct Enantioselective $\alpha$-Benzylation of Aldehydes with Alcohols. J. Am. Chem. Soc. 2018, 140 (9), 3322-3330. https://doi.org/10.1021/jacs.7b12768.

(29) a) Hioe, J.; Šakić, D.; Vrček, V.; Zipse, H. The Stability of Nitrogen-Centered Radicals. Org. Biomol. Chem. 2015, 13 (1) 157-169. https://doi.org/10.1039/C40B01656D; b) Vrček, V.; Zipse, H. Rearrangemements in Piperidine-Derived Nitrogen-Centered Radicals. A Quantum-Chemical Study. J. Org. Chem. 2009, 74 (8), 2947-2957. https://doi.org/10.1021/jo900349e.

(30) The original potential was expressed against the Ag/0.01 M $\mathrm{AgNO}_{3}$ and was here converted against SCE by adding +298 mV. See: Renneke, R. F.; Pasquali, M.; Hill, C. L Polyoxometalate Systems for the Catalytic Selective Production of Nonthermodynamic Alkenes from Alkanes. Nature of Excited-State Deactivation Processes and Control of Subsequent Thermal Processes in Polyoxometalate Photoredox Chemistry. J. Am. Chem. Soc. 1990, 112 (18), 6585-6594. https://doi.org/10.1021/ja00174a020.

(31) a) Keri, R. S.; Patil, M. R.; Patil, S. A.; Budagumpi, S. A Comprehensive Review in Current Developments of Benzothiazole-Based Molecules in Medicinal Chemistry. Eur. J. Med. Chem. 2015, 89, 207-251. https://doi.org/10.1016/j.ejmech.2014.10.059; b) Tariq, S.; Kamboj, P.; Amir, M. Therapeutic Advancement of Benzothiazole Derivatives in the Last Decennial Period. Arch. Pharm. (Weinheim). 2018, 1800170 https://doi.org/10.1002/ardp.201800170.

(32) a) Proctor, R. S. J.; Phipps, R. J. Recent Advances in Minisci-Type Reactions. Angew. Chem. Int. Ed. 2019, 58 (39) 13666-13699. https://doi.org/10.1002/anie.201900977; b) Duncton, M. A. J. Minisci Reactions: Versatile CHFunctionalizations for Medicinal Chemists. MedChemComm 2011, 2 (12), 1135. https://doi.org/10.1039/c1md00134e. 


\section{Table of Contents Entry}

PhotoElectroCatalysis via Hydrogen-Atom Transfer

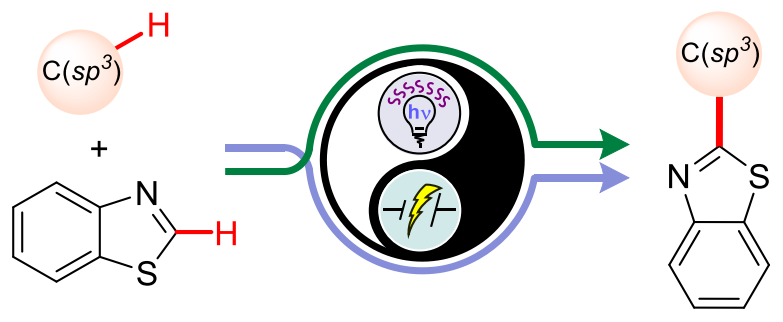

HAT • mechanistic analysis • cross-dehydrogenative coupling 